\title{
Correction to: Geodetic Time Series Analysis in Earth Sciences
}

Jean-Philippe Montillet and Machiel S. Bos

\section{Correction to:}

J.-P. Montillet and M. S. Bos (eds.), Geodetic Time Series

Analysis in Earth Sciences, Springer Geophysics, https://doi.org/10.1007/978-3-030-21718-1

In the original version of the book, the following belated corrections have been incorporated: Electronic Supplementary Materials have been included in Chapters 2 and 6, ESM logo has been added to the cover, and ESM information has been added to the opening page of both the chapters. The erratum chapters and book have been updated with the changes.

The updated versions of these chapters can be found at https://doi.org/10.1007/978-3-030-21718-1_2

https://doi.org/10.1007/978-3-030-21718-1_6 